\title{
Article
}

\section{Novel accessory safety footswitch permitting dual control of surgical electrical diathermy: an asset in risk management in surgical training?}

Eisawi, Abdalla, Aung, Myat and Canelo, Ruben

Available at https://clok.uclan.ac.uk/33909/

Eisawi, Abdalla, Aung, Myat and Canelo, Ruben (2020) Novel accessory safety footswitch permitting dual control of surgical electrical diathermy: an asset in risk management in surgical training? BMJ Innovations .

It is advisable to refer to the publisher's version if you intend to cite from the work. http://dx.doi.org/10.1136/bmjinnov-2019-000386

For more information about UCLan's research in this area go to http://www.uclan.ac.uk/researchgroups/ and search for < name of research Group>.

For information about Research generally at UCLan please go to http://www.uclan.ac.uk/research/

All outputs in CLoK are protected by Intellectual Property Rights law, including Copyright law. Copyright, IPR and Moral Rights for the works on this site are retained by the individual authors and/or other copyright owners. Terms and conditions for use of this material are defined in the policies page. 
A novel accessory safety foot-switch permitting dual-control of surgical electrical diathermy: an asset in risk management in surgical training?

1. Corresponding author: Abdalla Eisawi, Surgical Registrar, Scarborough General Hospital, Woodlands Drive, Scarborough YO12 6QL United Kingdom dreissawi@gmail.com 00447886266455

2. Myat Aung, Consultant Colorectal Surgeon, Cumberland Infirmary, Newtown Rd, Carlisle CA2 7HY United Kingdom. Myat.Aung@ncuh.nhs.uk

3. Rubin Canelo, Consultant Hepatobiliary Surgeon, Cumberland Infirmary, Newtown Rd, Carlisle CA2 7HY. RCanelo@uclan.ac.uk

Keywords: Accessory Footswitch; Abortive Diathermy; Safety Footswitch

Word Count: 1849 


\begin{abstract}
Introduction

Human error contributes to the majority of adverse events in the operating theatre environment. Many processes exist to limit the incidence of such adverse events. However, the role of technology and device advancement has been limited in this respect.

\section{Methods}

A dual-controlled accessory electrical diathermy foot switch (Abortive diathermy foot switch device or $\mathrm{ADF}$ ) concept was developed in an attempt to improve patient safety in theatre. The activation of the ADF allows a senior surgeon to control the activation of diathermy devices by a junior surgeon by deactivating diathermy devices when the ADF footswitch is operated.
\end{abstract}

\title{
Results
}

The ADF device was constructed as a final working and tested prototype in association with the local medical engineering department at the Cumberland Infirmary in Carlisle. The device was clinically tested during two separate theatre sessions involving five elective laparoscopic cholecystectomies.

\section{Conclusions}

We demonstrated the feasibility and functionality of the ADF device and propose a role in surgical training through potentially limiting surgical errors associated with the use of electrical diathermy during training and expanding accessible surgical experience. 


\section{Introduction}

Human error and communication failures cause or contribute to most adverse events in the operating theatre. Risk management processes have always been a crucial component in the modern medical system $[1,2]$. Communication failures in particular are common in the operating theatre and are the leading root cause of adverse events that can result in patient harm [3-12]. In one study, 30\% of intraoperative miscommunications resulted in a partial failure (e.g. poor timing, missing or inaccurate content, ineffective communication resulting in failure to resolve the issue) [6]. In order to address these failures processes were developed including timeouts, debriefings and checklists (WHO checklist being a prominent example and which incorporates the former two processes) [13, 14].

A conventional way of activating energy devices in the surgical operating theatre is the use of a foot or hand controlled switch. In the case of the footswitch this allows the operating surgeon to handle the energy device and other instruments at the same time. Energy devices are essential in allowing tissue dissection and maintaining haemostasis across many surgical disciplines for more than a century. From a safety perspective, complications due to energy-based devices are primarily related to thermal burns, haemorrhage, device failure, and fire [15]. Electrosurgery-related complications are relatively common, occurring in 2 to 5 per 1000 procedures [16]. The complication rate appears to be related to surgical experience, reaching a plateau after approximately 60 procedures [17].

When considering surgical training needs at the early spectrum of surgical training it is plausible to consider that early focused experience may shift the surgical learning curve to the left by leading to rapid accomplishment of surgical competencies. Traditionally more light is shed on the number of 
logbook cases rather than the individual of surgical involvement and quality/intensity of surgical supervision. This is mainly due to the fact that some of the latter factors are qualitative and difficult to measure.

The present paper describes the process of designing, rendering and the assembly of a novel device that is intended to allow senior surgeons to exert greater control in the training environment and potentially alter some of the undesirable metrics described above. To allow distinctive reference to the device we have chosen to call it the abortive diathermy footswitch (ADF).

\section{Materials and Methods}

The primary purpose of the ADF is to allow a second surgeon (usually senior or more experienced) to control the activation of energy devices by junior or trainee surgeons by utilising a secondary or an accessory foot or hand switch mechanism. Whilst in training it is understandable that junior trainees are still in a learning curve in terms of their experience and in view of that there is a potential of commission of errors.

The idea behind the device was realised following an experience by one of authors when he was a trainee performing a laparoscopic cholecystectomy under supervision by a senior surgeon. While the gallbladder was dissected off the gallbladder bed the wall of the gallbladder was inadvertently picked by the laparoscopic hook. This was recognised by the senior surgeon who promptly highlighted the error but only after the diathermy current was activated resulting in a hole in the gallbladder wall and subsequent leakage of bile.

Developing earlier (proof of principle) prototype iterations (2015-16) 
The first concept was built around developing a device allowing an experienced surgeon to control the use of energy devices. Earlier prototypes demonstrated this principle in the form of a custom designed hand controlled diathermy pencil that allows connectivity to a second hand or foot controlled switch operated by the experienced surgeon. In this case every time this facility is needed the device cannot be reused and will have to be disposed of. This would in turn raise questions concerning costs and uptake of the device given that such a device is an accessory rather than an essential component of surgical diathermy.

\section{Revised working prototype version (2017-18)}

The ADF prototype was revised to allow the accomplishment of the same dual control principles while addressing practical issues that can govern its application. Figure 1 provides a view of the standard diathermy footswitch setup connected to the diathermy generator. In contrast, the ADF prototype included a non-disposable setup utilising foot controlled switches (Figure 2: Yellow and blue circular pedals are the primary footswitches operated by the junior surgeon and the single rectangular accessory pedal is operated by senior surgeons) that can be connected directly to the energy device generator with an intervening (T connecting) control switch box (Figure 3). A provisional US patent has been obtained at this stage that included the final device setup as well as variations of the original concept.

\section{Results}

\section{Device development}

After finalising the determined concept and function of the device being aided by earlier iterations the medical engineering department was consulted to develop the device. A process of sourcing and assembly of the ADF device components was initiated. The components included the accessory 
footswitch, an electrical switch enclosure box that connects the accessory footswitch to the primary footswitch. Within the electrical switch enclosure box a Normally Closed (NC) switch (an essential electrical component allowing the required function of the accessory switch) was incorporated. When activated by the accessory footswitch this will open the circuit and deactivate the energy source device activated by a second operator (trainee or resident surgeon).

Therefore, the default system belongs to the trainee or resident surgeon who would activate the energy device using a primary footswitch but that could be interrupted when an experienced surgeon activates the accessory footswitch. In this case the accessory footswitch will have an emergency 'stop' function.

\section{Approval and testing standards}

The device was finalised and approved for use by the medical engineering department after it passed electrical testing standard requirements. Due to the inherent classification of the device as a low risk device it fell under the Medicines and Health Regulation Authority (MHRA) guidelines that allow in house manufacturing and clinical use of low risk devices without need to resort to clinical trials.

The NHS (Health Research Authority) Research Ethical Committee decision on the need of ethical approval was sought and the authors received a confirmation that and NHS research ethical approval is not needed. The authors retain confirmatory evidence of this. Further approval was sought at the level of the local clinical governance department at the Cumberland Infirmary, Carlisle, United Kingdom. A confirmation was received that no former approval was required to undertake this clinical evaluation. 


\section{Pilot clinical evaluation}

Prior to use and installation a verbal briefing was given to the relevant theatre staff about the introduction of the ADF device, its basic functionality and installation instructions. The ADF device was installed by one of the authors and developer of the device by connecting it to the Covidien ValleyLab force triad diathermy generator and the primary footswitch was connected to the electrical switch enclosure box (figure).

The ADF device was utilised during two elective theatre lists including five elective laparoscopic cholecystectomies that were at least partly performed by a trainee surgeon who was supervised by a consultant surgeon. One if the theatre lists was in the main theatre department while the other was in the day surgery theatre department.

The ADF device was activated on multiple occasions mainly to direct the trainee surgeon to modify his dissection strategy. There were no instances where specific surgical errors were committed and there were no near-miss incidents. In each of these occasions the ADF device continued to function properly during the aforementioned procedures. No specific adverse events were noted throughout the period of use. When not in use the device was initially stored in a tray underneath the generator but it was later left connected to the generator to encourage repeated use on the basis that the primary footswitch retains its basic functionality even if it was still connected to the device. This however led to a logistical issue when the entire generator was moved to other theatres utilised by other specialties.

\section{Discussion}


Consequences of surgical errors may be significant and may result in permanent harm or even a risk to the life of patients $[18,19]$. These direct action based surgical errors are not well reported in literature due to multiple factors including difficulty in quantifying such errors, the late onset of some of their associated complications (e.g. intestinal injury) and medicolegal implications [18]. When considering the theatre environment itself industrial tools are lacking in allowing a safer transition in the adoption of surgical skills. We propose that the ADF device may play a role in that respect and may primarily represent an asset in limiting action based and communication based errors.

The conventional way of managing that risk in the context of surgical training in the operating theatre is through direct commands by senior surgeons instructing the perceived correct way of utilising energy sources during each step of a surgical procedure. However, this has to be made in a timely fashion raising the prospect of harm being done if prompts are not passed through quickly as described in the real life example described above. In addition it is notable that if a certain degree of risk or difficulty is perceived during any given operation the senior surgeon may take over thus reducing the risk of training opportunities.

\section{"Error of omission" of surgical training opportunities?}

When considering that every surgical procedure represents a potential for acquisition of vital surgical skills it is reasonable to evaluate the reasons that can limit surgical training opportunities. Two of the commonest causes of such missed surgical opportunities include the perception that trainees may initially lack surgical experience or skills to permit them to accomplish certain parts of a given procedure or that the operation (or part of the operation) may be considered to be more complex and may exceed the ability of (even more senior) trainees. In that context both junior and senior trainees may be affected and thus the ADF device primary impact could be viewed as a risk management tool 
that can reduce the risk of error omission by omitting surgical training opportunities altogether in specific circumstances.

It is recognisable that the threshold above which senior operators take over a surgical case is a subjective metric and varies between individual senior surgeons involved. Through the development of the ADF device such threshold may be raised with the knowledge that senior surgeons can now exert greater control on the use of energy devices by their trainees. However we anticipate that not all surgeons may consider that there is a place for it in their training practice and it may be adopted by a risk averse subgroup of surgeons.

\section{Conclusion}

We conclude that the use of our dual-controlled accessory ADF foot switch device (and potentially expanding its use to various energy devices) may be a safety asset in surgical training by encouraging senior surgeons to provide a more inclusive surgical experience to trainees. The role of the ADF device in the operating theatre is palpable given its basic functionality and may be more significant in expanding training opportunities in the operating theatre rather than just simply considered to be an error preventing tool. 


\section{Contributorship}

Abdalla Eisawi contributed to the planning, conduct and reporting of the work described in the article. Abdalla Eisawi is responsible for the overall content as a guarantor. Myat Aung contributed to the planning and conduct of the work. Ruben Canelo contributed to the planning and conduct of the work.

\section{Funding}

None declared

\section{Competing Interests}

None declared

\section{Acknowledgement}

We would like to thank Mr Tony Sayers and his engineering team at the Cumberland Infirmary for his advice and work on developing the device and completing electrical safety testing. 


\section{References}

1. Kohn, LT, Corrigan, JM, Donaldson, MS, Eds; Committee on Quality of Health Care in America, Institute of Medicine. To Err Is Human: Building a Safer Health System. Washington, DC: National Academy Press; 1999.

2. Carayon P, Schoofs Hundt A, Karsh BT, et al. Work system design for patient safety: the SEIPS model. Qual Saf Health Care 2006; 15 Suppl 1:i50.

3. Neily J, Mills PD, Eldridge N, et al. Incorrect surgical procedures within and outside of the operating room. Arch Surg 2009; 144:1028.

4. Arriaga AF, Elbardissi AW, Regenbogen SE, et al. A policy-based intervention for the reduction of communication breakdowns in inpatient surgical care: results from a Harvard surgical safety collaborative. Ann Surg 2011; 253:849.

5. Greenberg CC, Regenbogen SE, Studdert DM, et al. Patterns of communication breakdowns resulting in injury to surgical patients. J Am Coll Surg 2007; 204:533.

6. Lingard L, Espin S, Whyte S, et al. Communication failures in the operating room: an observational classification of recurrent types and effects. Qual Saf Health Care 2004; 13:330.

7. Wauben LS, Dekker-van Doorn CM, van Wijngaarden JD, et al. Discrepant perceptions of communication, teamwork and situation awareness among surgical team members. Int J Qual Health Care 2011; 23:159.

8. Halverson AL, Casey JT, Andersson J, et al. Communication failure in the operating room. Surgery 2011; 149:305. 
9. Nagpal K, Vats A, Ahmed K, et al. A systematic quantitative assessment of risks associated with poor communication in surgical care. Arch Surg 2010; 145:582.

10. Gillespie BM, Chaboyer W, Murray P. Enhancing communication in surgery through team training interventions: a systematic literature review. AORN J 2010; 92:642.

11. Dayton E, Henriksen K. Communication failure: basic components, contributing factors, and the call for structure. Jt Comm J Qual Patient Saf 2007; 33:34.

12. Hickson GB, Jenkins AD. Identifying and addressing communication failures as a means of reducing unnecessary malpractice claims. N C Med J 2007; 68:362.

13. Barrington MJ, Uda Y, Pattullo SJ, Sites BD. Wrong-site regional anesthesia: review and recommendations for prevention? Curr Opin Anaesthesiol 2015; 28:670.

14. Abbott TEF, Ahmad T, Phull MK, et al. The surgical safety checklist and patient outcomes after surgery: a prospective observational cohort study, systematic review and meta-analysis. Br J Anaesth 2018; 120:146.

15. Overbey DM, Townsend NT, Chapman BC, et al. Surgical Energy-Based Device Injuries and Fatalities Reported to the Food and Drug Administration. J Am Coll Surg 2015; 221:197.

16. Nduka CC, Super PA, Monson JR, Darzi AW. Cause and prevention of electrosurgical injuries in laparoscopy. J Am Coll Surg 1994; 179:161.

17. Feldman LS, Brunt LM, Fuchshuber P, et al. Rationale for the fundamental use of surgical Energy $^{\mathrm{TM}}$ (FUSE) curriculum assessment: focus on safety. Surg Endosc 2013; 27:4054.

18. Tucker RD. Laparoscopic electrosurgical injuries: survey results and their implications. Surg Laparosc Endosc 1995; 5:311.

19. Krebs HB. Intestinal injury in gynecologic surgery: a ten-year experience. Am J Obstet Gynecol 1986; 155:509. 